\title{
Economia Circular: análise e aplicabilidade nas organizações sob a perspectiva da Teoria dos Stakeholders
}

\section{Circular Economy: analysis and applicability in organizations from the perspective of Stakeholder Theory}

\author{
Economía Circular: análisis y aplicabilidad en las \\ organizaciones desde la perspectiva de la Teoría de las Partes \\ Interesadas (stakeholders)
}

\author{
Sandro Costa Gonçalves ${ }^{1}$ \\ Evandro Roberto Tagliaferro ${ }^{2}$ \\ Leonice Domingos dos Santos Cintra Lima ${ }^{3}$ \\ Dora Inês Kozusny-Andreani ${ }^{4}$
}

\begin{abstract}
${ }^{1}$ Mestrando em Ciências Ambientais pela Universidade Brasil (UB). Pós-graduado em Gestão de Pessoas pelo Centro Universitário de Santo André (UNIA). Graduado em Administração de Empresas pelo Instituto de Ensino Superior de Santo André (IESA). Coordenador de Cursos

Tecnólogos em Gestão Financeira, Processos Gerenciais e Logística da Faculdade de Mauá (FAMA). Professor na FAMA e na Faculdade de Ribeirão Pires (FRP).E-mail: san.costa@uol.com.br, ORCID: http://orcid.org/0000-0001-5832-4305

${ }^{2}$ Doutor e suficiente investigador em Administração Empresarial e Comércio Internacional, com ênfase em Meio Ambiente, Economia, Desenvolvimento Humano e Sustentabilidade pela Universidad de Extremadura (UEx), Espanha. Especialista em Engenharia Ambiental e Sanitária pela Universidade Cândido Mendes (UCAM), RJ. Graduado em Engenharia Civil pela Faculdade de Engenharia de São José do Rio Preto, SP. Professor titular e pesquisador na Universidade Brasil (UB). E-mail: evandro.tagliaferro@universidadebrasil.edu.br, ORCID: http://orcid.org/0000-0003-2557-031X
\end{abstract}

${ }^{3}$ Doutora e Mestre em Serviço Social pela Faculdade de História, Direito e Serviço Social da Universidade Estadual Paulista "Júlio de Mesquita Filho" (UNESP). Realizou pesquisa em Nível de Doutorado na Universidade Católica de Portugal (UCP). Especialista em Metodologia do Serviço Social pela Faculdade de Serviço Social de Lins e em Administração Hospitalar pela Universidade de Ribeirão Preto. Graduada em Serviço Social pela UNESP. Professora e pesquisadora do Programa de Mestrado em Ciências Ambientais da Universidade Brasil (UB).E-mail: lecaclima@yahoo.com.br, ORCID: http://orcid.org/0000-0001-9647-6473

\footnotetext{
${ }^{4}$ Doutora em Agronomia pela Universidade Estadual Paulista "Júlio de Mesquita Filho" (UNESP). Mestre em Agronomia Genética e Melhoramento de Plantas pela UNESP. Graduada em Licenciatura em Genética pela Universidad Nacional de Misiones (UNaM). Professora titular e responsável pelos laboratórios de Microbiologia e Biotecnologia da Universidade Brasil (UB). Responsável pelo Programa de Iniciação Científica do campus de Fernandópolis da UB. Coordenadora da Comissão de Ética para Uso de Animais (CEUA/UB). Vice-coordenadora do curso do mestrado em Ciências Ambientais e professora titular dos mestrados em Ciências Ambientais e em Bioengenharia na UB. E-mail: doraines@terra.com.br, ORCID: http://orcid.org/0000-0001-8518-0984
} 
Resumo: O artigo apresenta uma investigação sobre o modelo de Economia Circular (EC) e sua aplicabilidade junto à Teoria dos Stakeholders. Buscou-se demonstrar os benefícios e dificuldades existentes em utilizar a circularidade dos mais variados produtos e serviços. Utilizaram-se estudos do estado da arte com o objetivo de delinear a pesquisa, apresentando o que há de mais relevante sobre os temas. Foram selecionados 20 trabalhos, entre teses e dissertações, obtendo-se dados para a compreensão e influência dos stakeholders nas organizações. Outras bibliografias deram suporte às análises realizadas. Verificou-se que a integração de seus interesses constitui o ponto primordial de seu desempenho como investidores e consumidores das marcas que operam com o modelo de EC. Foi possível averiguar a importância da EC nas organizações que zelam pelo equilíbrio entre as necessidades da sociedade, seus interesses e a preservação do ambiente, apresentando os principais conceitos de EC, e analisar sua aplicabilidade nas organizações sob a perspectiva dos stakeholders.

Palavras-chave: economia de berço ao berço; equilíbrio sustentável; lucro dos stakeholders.

\begin{abstract}
The article presents an investigation of the Circular Economy (CE) model and its applicability to the Stakeholders Theory. It sought to demonstrate the benefits and difficulties existent in the circularity use of several products and services. State-of-theart studies were used to design the research, presenting the most relevant issues on the theme. Twenty papers were selected, among theses and dissertations, obtaining data for the understanding of the stakeholders' influence in organizations. Other references supported the analyzes performed. The integration of their interests was found to be the main point of their performance as investors and consumers of the brands that operate with the CE model. It was possible to verify the importance of the CE in organizations that ensure the balance between the needs of society, its interests, and the preservation of the environment, presenting the main concepts of $\mathrm{CE}$, and analyze its applicability in organizations from the stakeholders' perspective.
\end{abstract}

Keywords: cradle-to-cradle economy; sustainable balance; stakeholder's profit.

Resumen: El articulo presenta una investigación acerca del modelo de Economía Circular (EC) y su aplicabilidad junto a la Teoría de las Partes Interesadas (stakeholders). Se ha buscado demostrar los beneficios y las dificultades existentes en usar la circularidad de los más variados productos y servicios. Se ha usado estudios del estado de la arte con el objetivo de delimitar la investigación, presentando lo que hay de más relevante acerca de los temas. Fueron seleccionados 20 trabajos, entre tesis y disertaciones, consiguiendo-se datos para la comprensión de la influencia de las partes interesadas en las organizaciones. Otras bibliografías han apoyado las analices realizadas. Fue verificado que la integración de sus intereses constituye el ponto primordial de su rendimiento como inversionistas y consumidores de las marcas que operan con el modelo de EC. Fue posible notar la importancia de la EC en las organizaciones que cuidan del equilibrio entre las necesidades de la sociedad, sus intereses y la preservación del medio ambiente, presentando los principales conceptos de EC, y analizar su aplicabilidad en las organizaciones en la perspectiva de las partes interesadas.

Palabras clave: economía de la cuna a la cuna; equilibrio sostenible; beneficio de las partes interesadas (stakeholders). 


\section{INTRODUÇÃO}

As discussões sobre a degradação do meio ambiente e o uso irrestrito dos recursos naturais estão cada vez mais intensas em todo o mundo. 0 consumismo e a busca em suprir necessidades pessoais têm colocado temas como preservação e consciência ambiental na pauta de muitos tratados internacionais, na busca de alternativas para a preservação da vida no planeta.

Neste contexto, surge um novo olhar e uma proposta de mudança nos padrões de produção e consumo global: os métodos de Economia Circular (EC).

A EC tem por objetivo a circularidade no uso de materiais e energias de uma forma direcionada, desde o delineamento dos produtos, na tentativa de minimizar danos recorrentes, até o descarte inadequado de resíduos, a poluição ambiental em grande escala, entre outros.

Apesar do conceito de EC não ser novo, sua adesão ainda é um grande desafio e amplia-se o debate em nível global, com maior ênfase, a partir do ano de 2017, principalmente em conferências internacionais que discutiram a questão ambiental.

As mudanças sociais e o surgimento das tecnologias de comunicação e informação, a ampliação e abertura de fronteiras econômicas e a aproximação dos mercados financeiros estabeleceram mudanças comportamentais e organizacionais relevantes, ocasionando, como uma das consequências, o impacto negativo ao meio ambiente. Assim, é determinante a atualização e reestruturação das formas de atuação dos gestores junto às organizações e comunidades em que estejam inseridos.

Na luta por soluções para problemas como o aquecimento global e as perdas da biodiversidade, as mudanças nas relações entre empresa e sociedade vêm afetando a gestão das organizações e, consequentemente, o papel do gestor, que, entre suas atribuições, tem de elaborar e implantar modelos de gestão com responsabilidade social e, ao mesmo tempo, garantir o sucesso da empresa.

Os moldes da EC vêm ao encontro dessa demanda dos gestores, que assumem uma rede de relações entre a empresa e seus stakeholders. A gestão das organizações se configura pela relação de troca entre os gestores e 
os stakeholders, ou seja, entre o dono da empresa, acionistas, empregados, fornecedores, clientes, financiadores, entre outros.

Desta forma, objetivou-se, pelo presente trabalho, apresentar os principais conceitos de EC e analisar sua aplicabilidade nas organizações sob a perspectiva dos stakeholders, assim como identificar seus benefícios na preservação do meio ambiente com essa nova concepção de gestão de negócios, em que os ganhos podem ser iguais para os envolvidos, em contraste ao modelo linear vigente.

\section{REFERENCIAL TEÓRICO}

O conceito de economia linear diz respeito a uma maneira de organização da sociedade que se baseia na extração crescente de recursos naturais, em que os produtos feitos a partir desses recursos são utilizados até serem descartados como resíduos. Nessa forma de economia, a maximização do valor dos produtos se dá pela maior quantidade de extração e produção (LEGNAIOLI, [s.d.]).

De acordo com a Associação Brasileira de Empresas de Limpeza Pública e Resíduos Especiais (ABRELPE, 2018), os quase três mil lixões que existem no Brasil são um forte indicativo de que existe algo errado no modelo atual de extração e produção. Nesse contexto, na Economia Linear (EL), os resíduos são gerados a todo momento, em volumes crescentes, sendo que o mau gerenciamento desses resíduos agrava o problema. Atualmente, mais de 3.300 cidades brasileiras recorrem a depósitos irregulares, como os lixões, para armazenar seus resíduos, já que os aterros sanitários não são suficientes para este modelo de descarte (BAST, 2018).

Nesse caso, a EL tem sido considerada como um modelo de organização econômica inviável, uma vez que os limites de regeneração do planeta, bem como as fontes de recursos naturais, mostram sinais de esgotamento, tornando insustentável a manutenção desse modelo econômico e todo o sistema de produção e consumo baseado em suas premissas.

Em contraponto a esse sistema em crise, surge a Economia Circular (EC). Um novo conceito caracterizado pelo uso de materiais em seu estágio final de consumo, em que o termo "resíduo" não existe, sendo substituído 
por "reaproveitável" ou "reciclável". Trata-se de uma abordagem de utilização de início sem fim, ou seja, "do berço ao berço" (Cradle-to-Cradle), em que o objetivo é a circulação de todos os materiais como nutrientes, em ciclos biológicos ou técnicos, não existindo a ideia de resíduo; tudo é continuamente nutriente para um novo ciclo (STAHEL, 2010).

Os estudos que favoreceram a criação do modelo de EC datam da década de 1970, quando se acentuou a preocupação com o meio ambiente e os recursos naturais disponíveis e necessários para as empresas e, respectivamente, para a humanidade. Iniciava-se então uma maior conscientização sobre a necessidade de discussão e reflexão sobre as questões ambientais. No entanto os trabalhos sobre EC mostraram-se mais relevantes no Brasil apenas na última década, havendo, ainda, uma incipiente literatura disponível sobre a temática (GUARDABASSIO, 2018).

Desse modo, Vincent et al. (2006), Scott (2013) e Datschefski (2001) convergem suas teorias e conceitos de sustentabilidade, confirmando a importância e necessidade da natureza e seus elementos como fonte na resolução de problemas ligados à sustentabilidade.

Os autores destacam a necessidade de observar com mais atenção a natureza e seus recursos, evidenciando um caminho para o futuro sustentável. Benyus (2002) considera que quanto maior for a semelhança entre o nosso mundo e o mundo natural, maior será a probabilidade de nele se sobreviver.

A EC engloba a responsabilidade da indústria em projetar seus produtos de forma sustentável. A introdução dos princípios sustentáveis nos produtos inicia-se ainda na fase do design e tem a potencialidade de criar novas oportunidades de negócio, agregando valor ao produto e gerando vantagens competitivas para as empresas, além de uma maior aceitação por parte dos consumidores (ELLEN MACARTHUR FOUNDATION [EMF], 2012).

Dyllick e Hockerts (2002), Nidumolu, Prahalad e Rangaswami (2009) e Scott (2013) descrevem que desenhar produtos ecointeligentes não é apenas uma questão ética, é uma atitude de competitividade e desempenho, com base em um novo padrão de qualidade e promovendo a sustentabilidade.

Por sua vez, enquanto discussão, o presente artigo caracteriza a necessidade de descrever o conceito de stakeholder, sendo o termo apresentado 
como indivíduos, ou grupo, que possam afetar a obtenção dos objetivos organizacionais ou que são afetados pelo processo de busca desses objetivos.

Freeman (1984) afirma que stakeholders são os grupos que têm direito legitimado sobre a organização. Todavia outra definição encontrada, como a dos autores Mitchell, Agle e Wood (1997), descreve que os stakeholders podem gerar interferência em uma organização, pela mediação de três atributos: poder, legitimidade e urgência.

Porém os principais objetivos encontrados nas pesquisas de stakeholders estão norteados para identificar quem são os stakeholders das empresas, e determinar quais os tipos de influências que eles exercem (ROWLEY, 1997).

Por fim, é importante descrever que o artigo não pretende esgotar as discussões sobre EC e stakeholders, observando que o papel desempenhado pelos stakeholders é importante para a construção de um modelo sustentável, identificando suas influências e priorizando as necessidades das partes envolvidas, empresas, sociedade e meio ambiente (DAMASCENO et. al., 2015).

\section{METODOLOGIA}

Optou-se por analisar trabalhos que qualifiquem as possibilidades em apresentar os principais conceitos de EC e analisar sua aplicabilidade nas organizações sob a perspectiva dos stakeholders. Estes são denominados de investigações de estudos do estado da arte que, segundo Ferreira (2002), são inventários descritivos com o objetivo de fazer um panorama das pesquisas já realizadas em torno de um tema específico.

Para a análise dos estudos da EC, foi realizado um levantamento bibliográfico, com vistas ao estudo do estado da arte, por meio de busca on-line no banco de dados da Biblioteca Digital Brasileira de Teses e Dissertações (BDTD), publicadas no período de 2010 a 2018, sendo excludentes artigos que fugiram ao tema e à característica propostos. O critério para a escolha desses trabalhos foi a relevância que ofereceram à pesquisa apresentada. Após a delimitação dos trabalhos, optou-se por analisar aqueles abaixo relacionados (Quadro 1). 
Economia Circular: análise e aplicabilidade nas organizações sob a perspectiva da Teoria dos Stakeholders

Quadro 1 - Teses, artigos e dissertações sobre Economia Circular selecionados por títulos/autores/ano

\begin{tabular}{|l|c|}
\hline \multicolumn{1}{|c|}{ Títulos } & Autores/Ano \\
\hline $\begin{array}{l}\text { A natureza como limite da economia: a contribuição de } \\
\text { Georgescu-Roegen }\end{array}$ & CECHIN, 2010 \\
\hline $\begin{array}{l}\text { A Economia Circular aplicada no Brasil: uma análise a } \\
\text { partir dos instrumentos legais existentes para a logística } \\
\text { reversa }\end{array}$ & AZEVEDO, 2015 \\
\hline $\begin{array}{l}\text { Economia Circular: uma nova filosofia de gestão para o } \\
\text { séc. XXI }\end{array}$ & $\begin{array}{c}\text { LEITÃO, } \\
\text { 2015 }\end{array}$ \\
\hline $\begin{array}{l}\text { Transição para a Economia Circular: possibilidades de } \\
\text { aplicação no setor de metais }\end{array}$ & SANTIAGO, 2015 \\
\hline $\begin{array}{l}\text { Aplicação dos princípios da Economia Circular em uma } \\
\text { indústria de veículos comerciais }\end{array}$ & BARDERI, 2017 \\
\hline $\begin{array}{l}\text { A Economia Circular e o cenário no Brasil e na Europa } \\
\text { Projetos alinhados com os preceitos da Economia } \\
\text { Circular }\end{array}$ & NERY; FREIRE, \\
\hline $\begin{array}{l}\text { Uma Economia Circular no Brasil: uma abordagem inicial } \\
\text { PEREIRA et al., } \\
\text { 2017 }\end{array}$ & EMF, 2017 \\
\hline $\begin{array}{l}\text { Alternativas para a gestão dos resíduos orgânicos } \\
\text { urbanos: um estudo de caso na cidade de Florianópolis }\end{array}$ & ZAMBON, 2017 \\
\hline $\begin{array}{l}\text { Economia Circular e Humanismo: regulação para práticas } \\
\text { empresariais sustentáveis a partir da filosofia empresarial } \\
\text { de Brunello Cucinelli }\end{array}$ & GIRELLI, 2018 \\
\hline
\end{tabular}

Fonte: Elaborado pelos autores.

Na sequência, foram listadas as outras teses e dissertações analisadas. Estas apresentam os estudos sobre a EC e a TS e sua aplicabilidade nas organizações, visando à apresentação de uma economia sustentável e ética, foco da pesquisa (Quadro 2). 
Quadro 2 - Teses, artigos e dissertações sobre stakeholders selecionados por títulos/autores/ano

\begin{tabular}{|c|c|}
\hline Títulos & Autores/Ano \\
\hline $\begin{array}{l}\text { Teoria dos stakeholders no contexto da governança } \\
\text { corporativa: um estudo de caso }\end{array}$ & LADEIRA, 2009 \\
\hline $\begin{array}{l}\text { Teoria dos Stakeholders e Responsabilidade Social:algumas } \\
\text { considerações para as organizações contemporâneas }\end{array}$ & $\begin{array}{l}\text { SILVA; GARCIA, } \\
2011\end{array}$ \\
\hline Um novo modelo de classificação de stakeholders & $\begin{array}{l}\text { MAINARDES et } \\
\text { al., } 2011\end{array}$ \\
\hline $\begin{array}{l}\text { Stakeholders e setor turístico brasileiro: uma investigação } \\
\text { na cidade de Londrina-PR }\end{array}$ & CINTRA, 2013 \\
\hline $\begin{array}{l}\text { Hospitalidade em venda direta: um estudo de casos } \\
\text { múltiplos sob a Teoria dos Stakeholders }\end{array}$ & MOLA, 2013 \\
\hline $\begin{array}{l}\text { Modelagem da rede de stakeholders envolvidos em } \\
\text { melhorias de transporte coletivo por ônibus }\end{array}$ & PEREIRA, 2015 \\
\hline $\begin{array}{l}\text { A aplicação do modelo de saliência de stakeholders em } \\
\text { gestores de bancos de varejo }\end{array}$ & $\begin{array}{l}\text { D'AMARIO; SO- } \\
\text { RANZ, } 2014\end{array}$ \\
\hline $\begin{array}{l}\text { Distribuição de valor para o stakeholder funcionário e } \\
\text { desempenho organizacional }\end{array}$ & SARTURI, 2016 \\
\hline $\begin{array}{l}\text { Capacidades organizacionais e a sinergia da criação de } \\
\text { valor para stakeholders }\end{array}$ & BARAKAT, 2018 \\
\hline $\begin{array}{l}\text { Análise dos stakeholders do Parque Tecnológico do Norte } \\
\text { Fluminense }\end{array}$ & SANCHES, 2018 \\
\hline
\end{tabular}

Fonte: Elaborado pelos autores.

Foram coletados, ainda, dados disponibilizados em acervos on-line, de domínio público e outros disponíveis para complementar a pesquisa bibliográfica, com base nas análises de estudiosos sobre os temas.

Por fim, foram analisados os 20 artigos selecionados: (a) dez artigos apontando suas considerações mais relevantes quanto ao estado do conhecimento sobre a Economia Circular e suas contribuições para uma vida sustentável e (b) dez artigos indicando suas considerações mais relevantes para o estado do conhecimento sobre a Teoria dos Stakeholders e sua aplicabilidade nas organizações, o que possibilitou alcançar os objetivos propostos. 


\section{RESULTADOS E DISCUSSÃO}

\subsection{Economia Circular}

Entre os temas mais recorrentes encontrados na análise dos materiais sobre a EC, destacam-se como resultado: histórico e conceitos sobre a EC, incentivos financeiros para as empresas com responsabilidade social e ambiental, ganância econômica ante os recursos naturais finitos, circularidade das cadeias produtivas, legislação ambiental, consumo consciente, Ellen MacArthur Foundation, EC na Europa, logística de reserva, coleta seletiva, dignidade humana, economia humanista, crescimento econômico infinito em um planeta finito, o valor do capital natural, modelos de economias sustentáveis, a capacidade de crescimento do planeta, o ciclo de vida dos resíduos, entre outros relativos à EC (Gráfico 1).

Gráfico 1 - Recorrência percentual de temas identificados nos dez artigos analisados
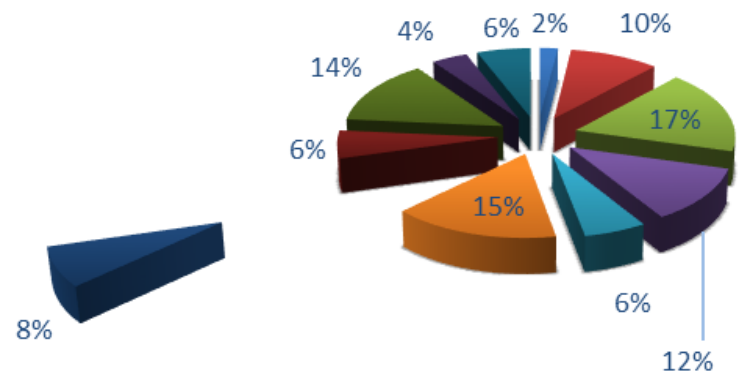

Incentivos Financeiros

- Conceitos EC

Histórico EC

- Responsabilidade Ambiental

- Legislação Ambiental

- Consumo Consciente

- Logística Reversa

- Coleta Seletiva

- Economias Sustentáveis

- Resíduos

- Capacidade Produtiva do Planeta

Fonte: Elaborado pelos autores.

Cechin (2010) defende a teoria sobre "a natureza como única limitante do processo econômico" e a temática das inter-relações entre economia e a natureza. O autor debate a problemática de uma vida sustentável e a limitação da aquisição de matérias-primas naturais para a manutenção de uma economia cada dia mais desenfreada, tratando em detalhes as ciências 
econômicas e suas maneiras para adequar a contemporaneidade a uma natureza finita. Descreve os recursos naturais como finitos, cuja exploração chegará a um pico em que o ritmo de exploração excederá a descoberta de depósitos acessíveis à ganância econômica.

Santiago (2015) trata da EC no setor de metais, ampliando o debate em relação às alternativas para o modelo de desenvolvimento de uma economia sustentável, sobre a hipótese de ser uma alternativa que permite dissociar o crescimento econômico do uso de recursos naturais, promovendo uma economia que é restaurativa e regenerativa ao planeta.

A autora explorou o tema sobre a transição da produção e do consumo de metais para um modelo circular, considerando ser uma tarefa importante, pois o mundo se encontra em plena urbanização e depende intrinsecamente dos metais para isso, formando parte significativa da base material da economia. Descreveu a crescente demanda por metais, tanto em volume quanto em tipos, atrelando-os ao crescimento econômico, expansão industrial e urbanização de países. Considera que a importância dos metais só aumenta no contexto atual, com crescente demanda para o futuro, com o direcionamento que se tem dado a uma economia de baixo carbono, cuja viabilidade necessita do desenvolvimento de tecnologias que dependem intrinsecamente do uso de metais, como aquelas ligadas ao uso, transformação e conservação de energias renováveis. E deixa registrada a viabilidade dos metais para a EC em diversos setores industriais, porém esclarece as preocupações dos impactos socioambientais das atividades extrativas e industriais de transformação dos minérios em metais, "[...] seja pela crescente dificuldade de se viabilizar a exploração mineral tanto por escassez de reservas de fácil acesso e baixo custo, como pela volatilidade dos preços desses materiais, por suas fontes serem finitas" (SANTIAGO, 2015). Aponta, assim, os metais secundários como a maneira mais eficiente de se promover circularidade nas cadeias de metais.

Já com Azevedo (2015) tem-se um estudo sobre a legislação brasileira existente, ante a aplicabilidade de uma economia restaurativa, dentro das perspectivas de uma "Logística de Reserva" para dimensionar sua funcionalidade. A autora destaca os princípios da EC que considera de maior relevância: 
Criação de modelos de negócios que agreguem valor ao produto manufaturado. Criação de produtos de múltiplas utilidades. Desenvolvimento de uma logística reversa que mantenha a qualidade e o custo de forma equilibrada. Coordenação dos atores dentro e entre as cadeias de suprimento para criar escala e identificar usos de maior valor (AZEVEDO, 2015, p. 4).

Conforme observa-se na Lei n. 12.305/2010, a logística reversa é um:

[...] instrumento de desenvolvimento econômico e social caracterizado por um conjunto de ações, procedimentos e meios destinados a viabilizar a coleta e a restituição dos resíduos sólidos ao setor empresarial, para reaproveitamento, em seu ciclo ou em outros ciclos produtivos, ou outra destinação final ambientalmente adequada (BRASIL, 2010).

Faz-se nceotar que a legislação já prevê normas regulamentadoras para que as empresas se adequem à circularidade de seus produtos, colocando-as como responsáveis pela coleta de seus resíduos. A autora aponta os consumidores como "peça chave no sistema de logística de reversa" (AZEVEDO, 2015, p. 10) e sua importância na utilização e na forma de descarte de seus materiais de consumo. Conclui sua pesquisa afirmando que é dever do "Poder Público, como garantidor da aplicação das regras e princípios previstos na Constituição de 1988 e na legislação, a iniciativa em direção à concretização da ideia de que valores biológicos e tecnológicos transcendam a vida útil de um produto ou serviço" (AZEVEDO, 2015, p. 14) forçando, assim, as organizações a pensarem na circularidade do que oferecem ao mercado de consumo.

Leitão (2015) se refere à EC como uma nova filosofia de gestão para o séc. XXI, constituindo um paradigma sobre as possibilidades futuras, em contraste com o modelo linear vigente, que se encontra ameaçado, devido à disponibilidade limitada de recursos naturais e limites do planeta em termos de capacidade de assimilação da poluição gerada por ela. Defende que "À tese do desenvolvimento descontrolado e ilimitado, tende a suceder cada vez mais a tese do desenvolvimento equilibrado e sustentável" (LEITÃO, 2015, p. 23). Essa autora tece significativas considerações sobre a EC e faz um minucioso relato de seu histórico, desde a década de 1960 até os dias atuais, em conformidade a apontar os horrores que a Economia Linear (EL) 
causa ao planeta, fazendo-nos refletir que a melhor forma de ainda conseguir viver em harmonia com a natureza é a preservação do meio ambiente.

Pereira, Moncunill e Monteiro (2017), sob a perspectiva da sustentabilidade, relatam com entusiasmo as expectativas propostas pela EC, que, por meio de várias estratégias de restruturação das formas de produção e consumo, objetiva reduzir o uso de matérias-primas e energia, diminuindo o impacto da sociedade de consumo sobre os recursos naturais do meio ambiente.

Nos estudos dos autores, destaca-se a relevância do Banco Nacional de Desenvolvimento Social (BNDES), que há duas décadas vem renovando seu comprometimento no apoio ao desenvolvimento sustentável da economia brasileira, por meio de diversos instrumentos, tanto na forma de renda fixa quanto variável, procurando promover a inovação, o respeito ao meio ambiente, a inclusão social, o progresso do parque industrial, assim como a evolução do provimento de serviços, nos mais diversos setores da economia.

Os autores concluíram a pesquisa afirmando a importância da sustentabilidade econômico-socioambiental do desenvolvimento no Brasil, considerando positiva a implementação de projetos alinhados com os preceitos da EC. Acrescentam os autores que, para concretizar tais apoios, o BNDES tem linhas financeiras de incentivo para empresas de qualquer porte, além de dispor de recursos humanos para auxiliar os entes públicos na estruturação do desenvolvimento sustentável e para a gestão de resíduos sólidos (PEREIRA; MONCUNILL; MONTEIRO, 2017).

Barderi (2017) tratou da aplicação dos princípios da EC em uma indústria de veículos comerciais, especificamente de caminhões, e observou que, ao aderir à EC, foi possível, para este setor, a redução de consumo de recursos naturais para a confecção de novas peças e componentes, a aplicação de logística reversa de peças usadas para a aquisição de peças remanufaturadas, o incentivo ao uso de oficinas de concessionárias, que têm controle operacional e ambiental, e a redução do descarte de resíduos inerentes às atividades de pós-venda da cadeia de valor do caminhão.

O autor estabelece critérios para que o desenvolvimento e a manufatura reúsem as peças que compõem componentes obsoletos, ou com falhas de qualidade, na remanufatura, evitando assim o sucateamento para 
empresas de reciclagem e a necessidade de retirar mais matéria-prima da natureza, agregando valor sustentável ao produto produzido.

Membros da Rede CE100 Brasil fizeram uma abordagem exploratória inicial sobre EC no Brasil, descrevendo o trabalho da Ellen MacArthur Foundation (EMF) com empresas, academias e governos a fim de construir um código de desenvolvimento para uma economia que seja restaurativa e regenerativa por princípio. A Fundação foi constituída em 2010, com o objetivo de acelerar a transição para a EC. O estudo se concentra em três setores importantes para a economia brasileira: agricultura e ativos da biodiversidade; edifícios e construção; e equipamentos eletroeletrônicos.

O programa CE100 Brasil foi lançado em outubro de 2015 e concebido especialmente para organizações que tenham identificado oportunidades no mercado brasileiro. O programa se desenvolve paralela e complementarmente à rede global CE100. Ele oferece um programa de colaboração pré-competitiva e inovação que reúne stakeholders chave de empresas, governos, da academia e de organizações afiliadas para atuarem como um laboratório vivo para a transição rumo à economia circular no Brasil. O programa CE100 Brasil possibilita às organizações membro desenvolver conhecimentos, superar desafios e aproveitar oportunidades associadas às características únicas do país. Conclusões preliminares mostram que a transição para a economia circular poderia gerar oportunidades de mais inovação e criação de valor no Brasil. Com características mercadológicas e sociais únicas, e capital natural incomparável, o Brasil é um cenário atraente para a exploração de oportunidades que a economia circular poderia trazer para a construção do capital econômico, social e natural (EMF, 2017, p. 3-4).

Na agricultura, a CE100 Brasil deu destaque às seguintes concepções de desempenho: ampliar esforços existentes em modelos de negócio regenerativos em agricultura e ativos da biodiversidade; estimular o desenvolvimento do incipiente setor de biointeligência; alavancar a tecnologia digital para destravar o potencial de EC na bioeconomia. Já no setor de edifícios e construção, destacaram-se: usar a lente da economia circular em investimentos de novos edifícios, para evitar entraves lineares; ampliar o acesso ao espaço construído ao aplicar princípios da EC; canalizar a tecnologia digital e as práticas inovadoras da EC para criar mais valor no setor de edifícios e construção. E para o setor de Equipamentos Eletroeletrônicos 
(EEE): a dinâmica específica do mercado brasileiro de EEE para criar novas oportunidades de negócio no contexto da EC; integrar a economia informal ao setor de EEE visando a uma colaboração mutuamente vantajosa; desenvolver novos modelos de negócio para ampliar o acesso e reduzir os custos dos produtos do setor de EEE; criar mecanismos para influenciar processos de design. (EMF, 2017, p. 12-3)

Com Nery e Freire (2017), tem-se a EC e o cenário no Brasil e na Europa; assim como Azevedo (2015), as autoras tratam da legislação vigente em relação à destinação dos resíduos sólidos e traçam um comparativo entre o Brasil e os países europeus. Elas nos apresentam em detalhes o conceito de "Logística de Reserva", como:

[...] uma nova área da logística empresarial que se preocupa em equacionar a multiplicidade de aspectos logísticos do retorno ao ciclo produtivo destes diferentes tipos de bens industriais, dos materiais constituintes dos mesmos e dos resíduos industriais, por meio da reutilização controlada do bem e de seus componentes ou da reciclagem dos materiais constituintes, dando origem a matérias-primas secundárias que se reintegrarão ao processo produtivo (NERY; FREIRE, 2017, p. 9).

A obra evidenciou que, em ambos os cenários, há uma legislação referente aos resíduos. Entretanto, o Brasil necessita de diversas leis e padrões estabelecidos pelo Conselho Nacional de Meio Ambiente (CONAMA), para uma lei/padrão reforçar a outra, enquanto, na Europa, uma diretriz específica sobre a tratativa de resíduos é suficiente para que o processo ocorra (2008/98/EU). O estudo concluiu ser necessário auxiliar as empresas a buscarem alternativas de implementação para se redesenharem industrialmente e inserirem a EC na cadeia produtiva, como também efetivar parcerias com canais de mídia que divulguem informação aos brasileiros sobre a importância da EC e sobre o tratamento dos resíduos, além de informações sobre os postos de coletas disponibilizados pelas empresas.

Girelli (2018) aborda a EC e o Humanismo, sob a filosofia empresarial de Brunello Cucinelli, o qual se inspirou na filosofia greco-romana, renascentista, na arte e na religião para dar vida, na Itália, a uma empresa que tem como princípio a dignidade da pessoa humana, mas que opera sem 
deixar de lado a busca pelo lucro, apreciando, assim, o elemento social do desenvolvimento sustentável. Considera que a EC trata das vertentes de ambiente e economia, carecendo de um elemento que trate o social, ou o "humano"; com isso, propõe uma parceria entre a EC e a Economia Humanista, assim preenchendo todas as lacunas existentes para gerar uma economia, de fato, sustentável. Enfatiza, ao concluir seu trabalho, que a Teoria da Economia Circular aliada à Teoria da Economia Humanista pode, de forma concomitante e complementar, constituir uma ferramenta valiosa para a implementação dos objetivos do desenvolvimento sustentável, visando promover um meio ambiente ecologicamente equilibrado; uma economia integrada e sólida; e uma sociedade que valorize e respeite a dignidade da pessoa humana.

Finalizando as dissertações sobre a EC, são apresentadas as reflexões de Zambon (2017), que relata em seu estudo de caso as alternativas para a gestão dos resíduos orgânicos urbanos, sob a ótica da EC, e os resíduos do ciclo biológico e a cadeia de resíduos orgânicos. Suas considerações identificam as principais tecnologias adotadas para a gestão de resíduos sólidos orgânicos, com destaque para os gerados nos centros urbanos, descrevendo os sistemas de gestão de resíduos orgânicos urbanos adotados em outros países, bem como as políticas adotadas. O autor descreve em detalhes a situação atual da gestão de resíduos orgânicos urbanos em Florianópolis (cidade de seu estudo de caso) e identificou iniciativas de compostagem para a circularidade dos resíduos orgânicos. Ele destaca diversas vantagens associadas ao reaproveitamento dos resíduos orgânicos, tal como o uso destes como fertilizantes ou condicionadores de solos na agricultura, constituindo uma forma de combater o empobrecimento dos solos - processo agravado pelo uso abusivo de fertilizantes minerais que, por sua vez, necessitam de elevada quantidade de energia para serem produzidos e distribuídos.

Diante das análises sobre EC, nota-se a urgente necessidade de transição da Economia Linear para a Economia Circular, objetivando alcançar resultados mais concretos na preservação de nosso planeta. A diferença entre essas duas economias é muito grande em relação à preservação ambiental (Figura 1). 
Figura 1 - Modelo de transição da Economia Linear para a Circular
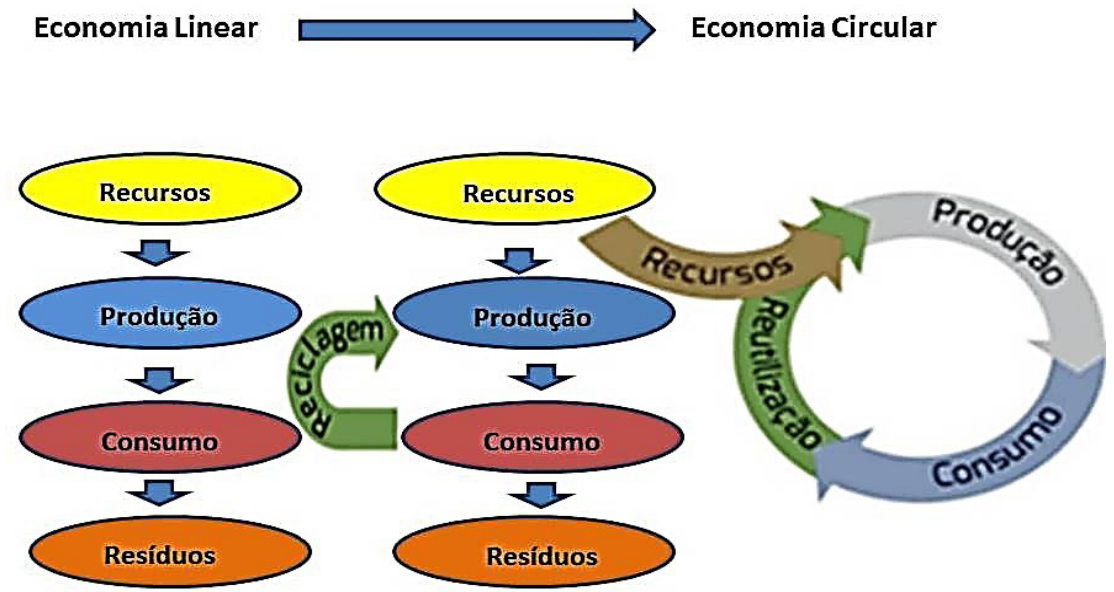

Fonte: Adaptado de Portal da Circular Economy Portugal (2019).

Minimizar os impactos negativos dos efeitos resultantes das práticas da Economia Linear exige grande empenho. Somente com a participação dos atores envolvidos nos processos sistêmicos de extração, produção, distribuição, consumo e pós-consumo a transição desse modelo para a EC pode se concretizar, resultando em avanços positivos na preservação e sustentabilidade do nosso meio ambiente, sociedade e economia. Neste contexto, o envolvimento dos stakeholders é de extrema importância, pois são eles que garantem a sustentabilidade econômica de qualquer segmento de produtos e/ou serviços.

Em se tratando da teoria dos Stakeholders, Ladeira (2009) descreve que "[...] stakeholders são considerados os proprietários investidores, que possuem como interesses: os dividendos ao longo do tempo, os ganhos de capital, a maximização do valor da empresa e o máximo retorno total".

Todavia há outras definições encontradas, algumas mais amplas, como a de Mitchell, Agle e Wood (1997), sugerindo que a interferência dos stakeholders em uma organização se dá pela mediação de três atributos: poder, legitimidade e urgência, os quais se pode descrever da seguinte maneira: (a) Poder: é a probabilidade que um ator tem dentro de um relacionamento social de estar numa posição de realizar sua própria vontade, apesar da resistência. 
(b) Legitimidade: é a de que um stakeholder legítimo é aquele cujas ações são vistas como apropriadas, adequadas e legítimas dentro de um sistema social constituído de normas, valores, opiniões e definições (SUCHMAN, 1995). (c) Urgência: é baseada na sensibilidade e criticidade de tempo em relação às demandas do stakeholder (JONES, 1995). É o grau com o qual o stakeholder pode reivindicar e ser imediatamente atendido. A combinação desses três atributos gera sete tipos diferentes de stakeholders (Figura 2):

Figura 2 - tipos de Stakeholder

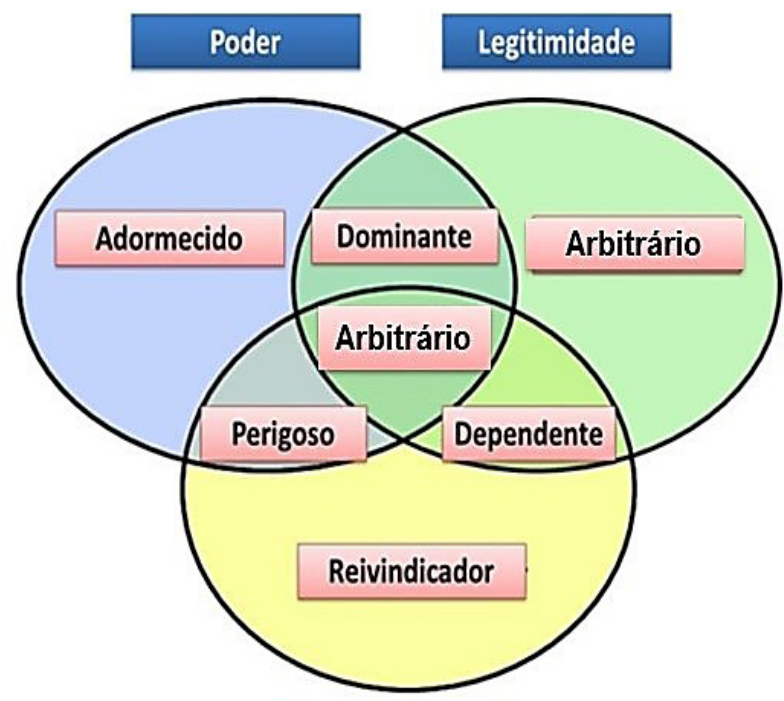

Urgência

Fonte: Adaptado de Damasceno et al. (2015)

Observa-se que o papel dos stakeholders são suas contribuições para a construção de um modelo sustentável. Assim sendo, para satisfazer os stakeholders, deve-se primeiro identificar aqueles que influenciam a organização, e assim priorizar suas necessidades.

\subsection{Teoria dos Stakeholders (TS)}

Em relação à TS (Teoria dos Stakeholders) destaca-se a recorrência das questões: Priorização de stakeholders, poder-legitimidade-urgência, 
saliência dos stakeholders, classificação dos stakeholders, importância na organização, stockholders, responsabilidade social, relacionamentos, venda direta, hospitalidade, institucionalismo sociológico, padrões de comportamento, normas e valores, crenças e pressupostos, capacidades organizacionais sinérgicas, novas organizações, entre outros.

Ladeira (2009) tratou da Teoria dos Stakeholders no contexto da Governança corporativa, dando destaque a várias vertentes de Gestão Estratégica que vem de encontro ao sucesso dos empreendimentos com governança corporativa. Objetivou identificar a importância da TS como diferencial estratégico, com análise das práticas de governança que agreguem valor e consolidem as estratégias propostas nas empresas estudadas.

Reconhecer a governança corporativa como uma tendência e buscar aliar os objetivos da organização às demandas dos stakeholders evidenciam os valores, princípios e processos que regem os mecanismos de gestão das empresas. O foco está na transparência, equidade e prestação de contas. A teoria dos stakeholders, no contexto da governança corporativa, voltada ao estudo da estratégia da organização, permite a identificação de estratégias direcionadas e fundamentadas em práticas corporativas. As competências essenciais, as disciplinas de valor, as estratégias de Ohmae e outras teorias permitem identificar e valorizar a importância da teoria dos stakeholders como basilar no meio empresarial e como parte integrante do planejamento estratégico em sua essência (LADEIRA, 2009, p. 10).

Os estudos apontam que a governança corporativa se baseia no cumprimento de suas práticas para aumentar o valor da empresa e garantir sua perenidade. Essas empresas possuem vantagem competitiva porque otimizam a estrutura e o custo de capital, promovem capacitações e identificam novas oportunidades. A governança corporativa assegura direitos de todos dentro de uma empresa, tanto acionistas quanto stakeholders. Uma das principais conclusões de Ladeira (2009) é que o modelo de governança adotado e seu código de conduta, que visam a atender a todos os stakeholders envolvidos, permitem maior foco dos funcionários nos valores e princípios da empresa.

Mainardes et al. (2011) consideram “Um Novo Modelo de Classificação de Stakeholders", estabelecendo um critério de prioridade dos stakeholders 
a serem atendidos nas organizações. A nova classificação proposta pelos autores considerou o método proposto por Whetten, em 1989, no seu ensaio intitulado "O que constitui uma contribuição teórica?". Nele se estabelece quatro elementos essenciais: fatores (variáveis constructos e conceitos); relação entre os fatores; dinâmicas que justificam a seleção dos fatores e as relações de causalidade entre eles; e, fatores temporais e contextuais que delimitam o modelo (que determinam o alcance e a extensão do modelo). Concluíram os autores que, de acordo com os princípios da TS, a gestão dos stakeholders exige uma classificação por importância, pois não é possível atender a todos ao mesmo tempo e na mesma medida.

Já Silva e Garcia (2011) falam sobre "TS e Responsabilidade Social”, em específico sobre o papel do gestor, que tem como uma de suas atribuições elaborar e implantar modelos de gestão empresarial, de tal forma que esses modelos garantam o sucesso da empresa, estabelecendo uma "uma rede de relações entre a empresa e seus stakeholders".

Os stockholders, que são os acionistas, teoria primeiramente abordada por Smith (1983, p. 379) quando afirmou que um empresário investe seu capital em função do lucro e só o fará "[...] no fomento daquela atividade cujo produto é suscetível de atingir o valor máximo". Ou seja, só investirá em um produto que apresentar perspectiva de maior retorno financeiro e no menor tempo possível. Ao discutir a responsabilidade social do capital e do trabalho, numa economia não planificada, denominada de livre mercado, a função social dos líderes sindicais é a de lutar pelos direitos da classe dos trabalhadores e a função social dos empresários e seus gestores é a de "[...] usar seus recursos e dedicar-se a atividades destinadas a aumentar seus lucros até onde permaneça dentro das regras do jogo, o que significa participar de uma competição livre e aberta, sem enganos ou fraude". Nessa ótica, portanto, respeitando-se as leis do país no qual a empresa atua, a única responsabilidade social dos gestores empresariais é o máximo lucro para os stockholders (SILVA; GARCIA, 2011, p. 9).

Os autores ainda destacam que no sistema econômico contemporâneo, o exclusivismo do lucro dos stockholders como única responsabilidade social empresarial não se sustenta mais, dado as rápidas mudanças do ecossistema terrestre e suas interligações. Tal fato suscita uma mudança de abordagem de interpretação do mundo e das coisas do mundo. 
A pesquisa de Mola (2013), para compreender qual a abrangência do termo nas relações comerciais ocorrentes nesse sistema comercial (venda direta), partindo do preceito de que a hospitalidade tem por função o estabelecimento de relacionamentos. A dissertação procurou explicar:

Que os aspectos particulares do comportamento humano tornam a atividade da venda direta uma oportunidade ao estudo da hospitalidade e que, por meio da hospitalidade, a venda direta forma um microcosmo no qual o relacionamento humano e o contato pessoal são a chave para o sucesso profissional - que (surpreendentemente para este modelo de negócio) nem sempre está ligado apenas ao retorno financeiro (MOLA, 2013, p. 20).

Comprovou-se a relevância do aspecto social na atividade mencionada, sob o enfoque de técnicas para conquista de clientes, mas a partir do comportamento presente nas relações humanas. "O paradigma da gestão de marketing desafiou a visão de que, embora os interesses de todos os stakeholders sejam válidos, relevantes ou estratégicos, eles não deixam de ser secundários" (MOLA, 2013, p. 45). Destaca-se que as relações pessoais criam um vínculo muito mais forte com os stakeholders do que qualquer outra estratégia econômica.

Cintra (2013) descreve os "Stakeholders e setor turístico brasileiro" delineando o campo organizacional do turismo a partir da TS e o institucionalismo sociológico. O autor retrata a expansão do turismo que pode trazer impactos positivos ou negativos à comunidade, gerando conflitos por interesses opostos. Para minimizar tais conflitos e buscar uma visão coletiva de desenvolvimento no setor se torna necessário envolver inúmeros stakeholders no processo de planejamento e gestão. Confronta as teorias no que tange o setor turístico, destacando a Teoria Institucional que incorpora a ideia de instituições e padrões de comportamento, de normas e de valores, crenças e pressupostos, nos quais se encontram imersos em organizações, grupos e indivíduos. Finaliza sua pesquisa destacando a importância da TS ao turismo no campo de sua investigação (Turismo em Londrina/PR), dando ênfase que conhecer os stakeholders e atender suas necessidades é a premissa ao sucesso de qualquer organização.

Em D’Amario e Soranz (2014), tem-se "A aplicação do modelo de saliência de stakeholders em gestores de bancos de varejo", analisando a 
semelhança na percepção entre gestores e diretores sobre priorização de stakeholders, por meio de três atributos: poder, legitimidade e urgência. Os autores dão enfoque no equilíbrio de interesses das partes envolvidas, como um processo de avaliação no qual se deve pesar e avaliar as reivindicações daqueles que têm alguma participação nas ações da organização. No estudo de caso, foram caracterizadas as lógicas institucionais em populações organizacionais diferentes, para verificar a percepção de saliência de stakeholders em outros contextos, de maneira prática e eficiente.

Sarturi (2016) nos traz reflexões sobre a "distribuição de valor para o stakeholders funcionário e desempenho organizacional", considerando que o stakeholders funcionário é o que mais contribui na criação de valores para a empresa. A autora estabeleceu, para a relevância de sua pesquisa, as convergências entre as TS, Gestão Estratégica de Recursos Humanos e Teoria Motivacional, enaltecendo que funcionários bem treinados e motivados se comprometem com o sucesso da empresa, assim este stakeholders pode se tornar um grande aliado, tendo a necessidade de estarmos atentos a este grande potencial que defenderá os ideais da empresa tornando-a valorosa aos olhos dos demais stakeholders.

Com Barakat (2018) observou-se a capacidade organizacional e a sinergia da criação de valor para stakeholders, estabelecendo uma proposta que compõe as principais capacidades para o alcance desta sinergia: capacidade de engajamento, capacidade de conhecimento, capacidade de integridade e capacidade de adaptação. Estar de posse de todas essas capacidades é a definição mais adequada de uma organização sinérgica onde todos os stakeholders que a ela pertence conduz suas ações simultaneamente, buscando beneficiar todo o conjunto, de modo que seu efeito seja maior que a soma dos efeitos de cada um dos stakeholders isoladamente. A tese é concluída com a teoria de que é necessário focar na sinergia entre os stakeholders e não em seus pontos conflitantes, o que naturalmente vem sendo perpetuado desde a criação da TS, a questão básica é a criação de valores na cadeia de stakeholders e isso será mais facilmente alcançado se os interesses individuais derem mais espaço ao interesse coletivo.

Por fim tem-se a destacar Sanches (2018) que nos apresenta sua análise dos stakeholders do Parque Tecnológico do Norte Fluminense (PTNF), 
procurando definir e caracterizar os stakeholders mais importantes que atuam no processo de implementação do parque. Para alcançar os resultados esperados o autor aplicou dois modelos de análise de stakeholders: o modelo de Mitchell, Agle e Wood (1997), conhecido também como modelo de saliência de stakeholders; e o modelo de Frooman, de 1999.

O primeiro modelo teve como objetivo a identificação e classificação dos stakeholders a partir de três atributos, aqui já discutidos (poder, legitimidade e urgência). O segundo modelo usou os níveis de dependência de recursos para determinar o poder de influência das partes interessadas, além de apontar as estratégias que elas podem adotar para influenciar a organização (SANCHES, 2018, p. 7).

A maior expectativa do autor foi a compreensão dos anseios e comportamentos das partes interessadas na implementação de um projeto de uma nova organização ou empreendimento, já que pessoas distintas têm anseios distintos, e responder às questões conflitantes deste processo, que geram tantas lacunas, é importante para a estabilidade de empreendimentos bem-sucedidos.

\section{CONSIDERAÇÕES FINAIS}

Ao concluir as análises sobre o estado do conhecimento da Economia Circular, assim como da Teoria dos Stakeholders, foi possível elencar possibilidades para o enquadramento da aplicabilidade nas organizações que praticam a EC sob a perspectiva da TS.

Muitos autores tentaram desenvolver modelos para identificação e análise dos stakeholders nas organizações, uma vez que isso se tornou um aspecto importante nas etapas do processo de tomada de decisão. Todos estes estudos dão destaque ao autor Freeman, que foi o primeiro a falar sobre a TS, na década de 1980, estabelecendo a relação entre vários indivíduos envolvidos em uma organização e que apresentam contribuições ou dificuldades para o alcance dos objetivos.

O recorte feito para este estudo mostrou apenas dez publicações sobre EC e dez sobre a TS, de um total de mais de 2.000 publicações em Ensino Superior nas áreas de administração, negócios, economia e meio ambiente, do banco de dados original. O critério de análise, primeiramente, 
foi a leitura dos resumos, das introduções e das considerações finais. Por fim, averiguou-se a relevância do trabalho no seu contexto geral, consistindo em estudos realizados sobre conhecer as possibilidades da aplicabilidade nas organizações que praticam a EC, sob a perspectiva da TS, sendo este um estudo para compreender melhor essa aplicabilidade, visto que não foi encontrado nenhum estudo, nos acervos consultados, que convergisse os dois temas, sendo sugeridas mais pesquisas e/ou produções acadêmicas que contemplem essa convergência.

A pesquisa revela que o desenvolvimento sustentável, nas organizações modernas, não se resume somente à conotação ambiental, mas transformou-se em parte dos objetivos e desafios das empresas para que se garanta a viabilidade do negócio, promovendo inclusive a definição de valores organizacionais. A tendência para o futuro é transformar o conhecimento sobre desenvolvimento sustentável em um pré-requisito para ser trabalhado nas empresas. Elevar o padrão de excelência em gestão com todos os stakeholders pode se tornar uma fonte de informação, que ajudará a organização a reduzir os impactos da sua atividade, demostrando ser imperativo sua aplicabilidade para uma conscientização em larga escala e alcance eficaz na transposição para a economia de berço ao berço.

Desta forma, a responsabilidade social é algo que engloba apenas os stakeholders envolvidos em sua unidade corporativa, porém é necessário se atentar para o fato de que a comunidade também é um dos stakeholders da organização, e de fundamental importância. Preocupar-se com a sociedade é vital, e também com os empregados, os fornecedores, os acionistas, os consumidores e o governo, que precisam ter suas necessidades identificadas e satisfeitas a fim de que seja otimizado o tempo na busca pelo sucesso amplo e conjunto.

Se o sucesso das organizações envolver as necessidades de ações sustentáveis e a conscientização dos stakeholders consumidores, o futuro do planeta estará mais bem amparado, e a valoração dessas empresas ante o mercado consumidor se tornará um atraente empreendimento para angariar cada vez mais stakeholders. Empresas bem-vistas no mercado, com compromisso social em relação ao meio ambiente, tem se destacado e atraído cada vez mais investidores e consumidores. 
O estudo realizado não esgota o assunto, a dimensão do acervo existente aponta para a possibilidade de outras novas pesquisas sobre o tema que tomem como referência esses estudos, considerando a EC uma proposta fundamental na remediação dos problemas ambientais na atualidade e que tem, em seus stakeholders, os maiores incentivadores para que ela seja alcançada.

Esta pesquisa abordou a TS, pela qual o gestor é visto como um investidor organizacional e precisa mudar o paradigma em função da sustentabilidade, e não somente do lucro, sendo esta a melhor estratégia na aplicabilidade da EC entre os diversos stakeholders e a integração de seus diferentes interesses como elemento central. A responsabilidade social do gestor, explicitada na EC, é trabalhada nesse contexto, como um elemento de equilíbrio entre os interesses dos acionistas e o da sociedade, pois acredita-se que, aumentando o valor da empresa perante a sociedade, aumenta-se também o valor das ações dela e, consequentemente, o lucro dos stackeholders.

Observou-se relação entre o modelo EC e a TS, considerando que a efetividade do modelo de EC não está condicionada somente ao fator econômico, mas também à legitimidade ou não dos stakeholders, o que evidencia a importância desses no processo. E este modelo de economia condiciona o interesse de cada vez mais stakeholders se comprometerem com ela. Assim notou-se, a princípio, que alguns stakeholders são mais influentes que outros e que isto pode ser um fator positivo ou negativo, uma vez que o conceito EC afirma a importância do modelo para economia, no entanto não leva em consideração a influência dos stakeholders. Já a TS evidencia a importância e a influência desses como fator preponderante na efetividade de qualquer processo organizacional.

Assim, considerando o avançado estágio dos seculares descuidos ambientais e o comprometimento das possibilidades de vida para as futuras gerações em face da finitude dos recursos naturais, o estudo demonstra a relevância das pesquisas sobre o tema, apontando a importância de novos estudos. Confirma também que a EC nas organizações que zelam pelo equilíbrio entre as necessidades da sociedade, seus interesses e a preservação do ambiente apresenta uma opção de negócios promissora e 
Economia Circular: análise e aplicabilidade nas organizações sob a perspectiva da Teoria dos Stakeholders

que preserva o nosso maior patrimônio, o meio ambiente, alcançando os objetivos propostos.

\section{REFERÊNCIAS}

ASSOCIAÇÃO BRASILEIRA DE EMPRESAS DE LIMPEZA PÚBLICA E RESÍDUOS ESPECIAIS [ABRELPE]. Panorama dos Resíduos Sólidos no Brasil. Abrelpe, [s.l.], 2018. Disponível em: http://abrelpe.org.br/panorama/. Acesso em: 16 jul. 2019.

AZEVEDO, J. L. A Economia Circular Aplicada no Brasil: uma análise a partir dos instrumentos legais existentes para a logística reversa. In: CONGRESSO NACIONAL DE EXCELÊNCIA EM GESTÃO, 11., 13-14 ago. 2015, Rio de Janeiro. Anais [...]. Rio de Janeiro, 2015. Disponível em: http://www.inovarse.org/node/3815. Acesso em: jul. 2019.

BARAKAT, S. R. Capacidades organizacionais e a sinergia da criação de valor para stakeholders. 2018. Tese (Doutorado em Ciências Sociais Aplicadas) - Universidade de São Paulo, São Paulo, SP, 2018.

BARDERI, M. T. Aplicação dos princípios da Economia Circular em uma indústria de veículos comerciais. 2017. Dissertação (Mestrado em Administração de Empresas) Centro Universitário da Fundação Educacional Inaciana Padre Saboia de Medeiros, São Bernardo do Campo, SP, 2017.

BRASIL. Lei n. 12.305, de 2 de agosto de 2010. Política Nacional de Resíduos Sólidos. Brasília-DF, 2010. Disponível em: http://www.planalto.gov.br/ccivil_03/_ato20072010/2010/lei/l12305.htm. Acesso em: 30 jun. 2021.

BAST, E. Brasil tem quase 3 mil lixões em 1.600 cidades. G1 (Globo), Rio de Janeiro, 26 fev. 2018. Disponível em: https://g1.globo.com/natureza/noticia/2018/09/14/ brasil-tem-quase-3-mil-lixoes-em-1600-cidades-diz-relatorio.ghtml. Acesso em: 15 maio 2019.

BENYUS, J. M. Biomimicry: innovation inspired by Nature. Nova York: Morrow, 2002.

CECHIN, A. A natureza como limite da economia: a contribuição de GeorgescuRoegen. São Paulo: Senac, 2010.

CINTRA, R. F. Stakeholders e setor turístico brasileiro: uma investigação na cidade de Londrina-PR. 2013. Tese (Doutorado em Administração) - Universidade Estadual de Londrina, Londrina, PR, 2013. 
D'AMARIO, E. Q.; SORANZ, R. F. A aplicação do modelo de saliência de stakeholders em gestores de bancos de varejo. In: ENCONTRO INTERNACIONAL SOBRE GESTÃO EMPRESARIAL E MEIO AMBIENTE, 16., 1-3 dez. 2014, São Paulo. Anais [...]. São Paulo: ENGEMA, 2014.

DAMASCENO, A. B.; MACAPUNA. C. A. B.; JULIÃO, M. S.; PEREIRA, M. C. Tipos de Stakeholder. 2015. Dissertação (Especialização em Gestão e Governança de Tecnologia da Informação) - Centro Universitário Senac, Santo Amaro, SP, 2015.

DATSCHEFSKI, E. The total beauty of sustainable products. Crans-près-Celigny: Rotovision, 2001.

DYLLICK, T.; HOCKERTS, K. Beyond the business case for corporate sustainability. Business Strategy and the Environment, v. 11, n. 2, p. 131-41, 2002.

ELLEN MACARTHUR FOUNDATION [EMF]. Towards the circular economy: economic and business rationale for an accelerated transition. Cowes: EMF, 2012. V. 1.

ELLEN MACARTHUR FOUNDATION [EMF]. Uma Economia Circular no Brasil: uma abordagem exploratória inicial. [s.l.]: EMF, 2017. Disponível em: https://www. ellenmacarthurfoundation.org/assets/downloads/languages/Uma-EconomiaCircular-no-Brasil_Uma-Exploracao-Inicial.pdf. Acesso em: jul. 2019.

FERREIRA, N. S. A. As pesquisas denominadas "estado da arte". Revista Educação \& Sociedade, Campinas, v. 23, n. 79, p. 257-72, ago. 2002.

FREEMAN, R. E. Strategic Management: a stakeholder approach. Boston: Pitman, 1984.

GIRELLI, C. S. Economia Circular e Humanismo: regulação para práticas empresariais sustentáveis a partir da filosofia empresarial de Brunello Cucinelli. 2018. Dissertação (Mestrado em Direito) - Universidade de Passo Fundo, Passo Fundo, RS, 2018.

GUARDABASSIO, E. V. Gestão Pública de Resíduos Sólidos Urbanos na região do Grande ABC. São Paulo: Todas as Musas, 2018.

JONES, T. M. Instrumental stakeholder theory: a synthesis of ethics and economics. The Academy of Management Review, Nova York, v. 20, n. 2, p. 404-37, 1995.

LADEIRA, D. L. Teoria dos stakeholders no contexto da governança corporativa: um estudo de caso. 2009. Dissertação (Mestrado em Administração) - Fundação Mineira de Educação e Cultura, Belo Horizonte, MG, 2009. 
Economia Circular: análise e aplicabilidade nas organizações sob a perspectiva da Teoria dos Stakeholders

LEGNAIOLI, Stella. Economia linear: o que é e por que é preciso mudar. eCycle, [s.l.], [s.d.]. Disponível em: https://www.ecycle.com.br/index.php?option=com_conten t\&task=view\&id=7073\&ltemid=1222. Acesso em: 10 jun. 2019.

LEITÃO, A. Economia circular: uma nova filosofia de gestão para o séc. XXI. Portuguese Journal of Finance, Management and Accounting, Lisboa, v. 1, n. 2, p. 149-71, 2015.

MAINARDES, E. W.; ALVES, H.; RAPOSO, M.; DOMINGUES, M. J. C. S. Um novo modelo de classificação de stakeholders. In: ENCONTRO DE ESTUDOS EM ESTRATÉGIA, 5., 15-17 maio 2011, Porto Alegre. Anais [...]. Porto Alegre, 2011

MITCHELL, R. K.; AGLE, B. R.; WOOD, D. J. Toward a theory of stakeholder identification and salience: defining the principle of who and what really counts. Academy of Management Review, Nova York, v. 22, n. 4, p. 853-86, 1997.

MOLA, J. L. Hospitalidade em venda direta: um estudo de casos múltiplos sob a teoria dos stakeholders. 2013. Dissertação (Mestrado em Hospitalidade) Universidade Anhembi Morumbi, São Paulo, SP, 2013.

NERY, S. M.; FREIRE, A. S. A Economia Circular e o cenário no Brasil e na Europa. In: ENCONTRO NACIONAL DE ENGENHARIA DE PRODUÇÃO [ENEGEP], 27., 10-13 out. 2017, Joinville, SC. Anais [...]. Joinville: ENEGEP, 2017

NIDUMOLU, R.; PRAHALAD, C. K.; RANGASWAMI, M. R. Why sustainability is now the key driver of innovation. Harvard Business Review, Cambridge, v. 87, n. 9, p. 25-34, 2009.

PEREIRA, F.; MONCUNILL, M. F.; MONTEIRO, S. A. T. Projetos alinhados com os preceitos da economia circular. In: LUZ, Beatriz Visconti (Org.). Economia circular Holanda - Brasil: da teoria à prática. Rio de Janeiro: Exchange 4 Change Brasil, 2017. p. 89-95.

PORTAL DA CIRCULAR ECONOMY PORTUGAL. Modelo de transição da economia linear para a circular, 2019.

ROWLEY, T. Moving beyond dyadic ties: a network theory of stakeholder influences. Academy of Management Review, New York, v. 22, n. 4, p. 887-910, 1997.

SANCHES, R. S. Análise dos stakeholders do parque tecnológico do norte Fluminense. 2018. Dissertação (Mestrado em Engenharia de Produção) - Universidade Estadual do Norte Fluminense Darcy Ribeiro, Campos dos Goytacazes, RJ, 2018. 
SANTIAGO, L. S. P. Transição para a Economia Circular: possibilidades de aplicação no setor de metais. 2015. Dissertação (Mestrado Profissional em Práticas em Desenvolvimento Sustentável) - Universidade Federal Rural do Rio de Janeiro, Rio de Janeiro, RJ, 2015.

SARTURI, G. Distribuição de valor para o stakeholders funcionário e desempenho organizacional. 2016. Tese (Doutorado em Ciências Sociais Aplicadas) - Universidade de São Paulo, São Paulo, SP, 2016.

SCOTT, J. T. The sustainable business: a practioner's guide to achieving long-term profitability and competitiveness. 2. ed. Sheffield: Greenleaf Publishing Limited, 2013.

SILVA, A. C.; GARCIA, R. A. M. Teoria dos Stakeholders e responsabilidade social: algumas considerações para as organizações contemporâneas. 2011. Monografia (MBA Executivo em Gestão Empresarial) - Universidade Católica Dom Bosco, Campo Grande, MS, 2011.

STAHEL, W. R. The performance economy. London: Palgrave McMillan, 2010.

SUCHMAN, M. C. Managing legitimacy: strategic and institutional approaches. Academy of Management Journal, New York, v. 20, p. 571-610, 1995.

VINCENT, J. F.; BOGATYREVA, O. A.; BOGATYREV, N. R.; BOWYER, A.; PAHL, A. K. Biomimetics: its practice and theory. Journal of the Royal Society Interface, New York, v. 3, n. 9, p. 471-82, 2006.

ZAMBON, M. M. Alternativas para a gestão dos Resíduos Orgânicos Urbanos: um estudo de caso na cidade de Florianópolis. Dissertação (Mestrado em Meio Ambiente) - Universidade Federal de Florianópolis, Florianópolis, SC, 2017. 